\title{
Shift in Conformational Equilibrium Induces Constitutive Activity of G- Protein-Coupled Receptor, Rhodopsin
}

\section{$\operatorname{AUTHOR}(S)$ :}

Maeda, Ryo; Hiroshima, Michio; Yamashita, Takahiro; Wada, Akimori; Sako, Yasushi; Shichida, Yoshinori; Imamoto, Yasushi

\section{CITATION:}

Maeda, Ryo ...[et al]. Shift in Conformational Equilibrium Induces Constitutive Activity of G-Protein-Coupled Receptor, Rhodopsin. The Journal of Physical Chemistry B 2018, 122(18): 4838-4843

\section{ISSUE DATE:}

2018-05-10

URL:

http://hdl.handle.net/2433/243174

\section{RIGHT:}

This document is the Accepted Manuscript version of a Published Work that appeared in final form in The Journal of Physical Chemistry B, copyright (c) American Chemical Society after peer review and technical editing by the publisher. To access the final edited and published work see https://doi.org/10.1021/acs.jpcb.8b02819.; この論文は出版社版であ りません。引用の際には出版社版をご確認ご利用ください。; This is not the published version. Please cite only the published version. 


\section{Shift in Conformational Equilibrium Induces Constitutive}

\section{Activity of G-Protein Coupled Receptor, Rhodopsin}

Ryo Maeda, ${ }^{\dagger, \ddagger}$ Michio Hiroshima,,$^{\ddagger, \|}$ Takahiro Yamashita, ${ }^{\dagger}$ Akimori Wada, ${ }^{\S}$ Yasushi Sako, ${ }^{\ddagger}$ Yoshinori Shichida, ${ }^{\dagger, \perp}$ and Yasushi Imamoto ${ }^{*},+$

${ }^{\dagger}$ Department of Biophysics, Graduate School of Science, Kyoto University, Kyoto, Japan, ${ }^{\ddagger}$ Cellular Informatics Laboratory, RIKEN, Wako, Saitama, Japan, "Laboratory for Cell Signaling Dynamics, RIKEN Quantitative Biology Center, Suita, Osaka, Japan, ${ }^{\S}$ Laboratory of Organic Chemistry for Life Science, Kobe Pharmaceutical University, Kobe, Hyogo, Japan, ${ }^{\perp}$ Research Organization for Science and Technology, Ritsumeikan University, Kusatsu, Shiga, Japan. 
ABSTRACT: Constitutively active mutants (CAMs) of G-protein coupled receptors (GPCRs), cause various kinds of diseases. Rhodopsin, a light-absorbing GPCR in animal retina, has retinal as an endogenous ligand; only very low levels of activation of G-protein can be obtained with the ligandfree opsin. However, the CAM of opsin activates G-protein much more efficiently than the wild type but the mechanism underlying this remains unclear. The present work revisits the constitutive activity of rhodopsin from the standpoint of conformational dynamics. Single-molecule observation of the M257Y mutant of bovine rhodopsin demonstrated that the switch between active and inactive conformations frequently occurred in M257Y opsin, and frequent generation of the active state results in the population shift towards the active state, which accounts for the constitutive activity of M257Y opsin. Our findings demonstrate that the protein function has a direct connection with the structural dynamics. 


\section{INTRODUCTION}

G protein coupled receptors (GPCRs) are ubiquitous cell surface receptor proteins with a common seven-transmembrane domain structural motif. They respond to specific ligands as stimuli and activate their cognate $G$ proteins, which initiate the signal transduction cascade in the cell. GPCRs act as molecular switches and should not exhibit basal activity in the absence of stimuli to improve the sensitivity by eliminating the noise. It is especially essential for a lightabsorbing GPCR in retinal rod cells, rhodopsin, responsible for the single photon response of the cell. However, it is well known that some mutations of GPCRs result in inherent basal activity ${ }^{1-6}$. These mutants are called constitutively active mutants (CAMs), which exhibit significant G protein activation effect in the absence of ligand. So far, several CAMs have been identified through pathological analysis as well as mutational characterization of GPCRs. Characterization of CAMs is important because CAMs often cause diseases, e.g. CAM of rhodopsin causes autosomal dominant retinitis pigmentosa or night blindness ${ }^{7}$. One of well-known CAMs of rhodopsin, M257Y, shows high constitutive activity and is characterized as an experimental model of CAM of GPCRs ${ }^{3,8-10}$.

While most GPCRs are activated by diffusible ligands, the activity of rhodopsin is regulated by the chromophore retinal, which acts as an endogenous ligand. In the dark state, retinal is in 11-cis configuration and acts as an inverse agonist. On photon absorption, the chromophore is isomerized to the all-trans form, resulting in the formation of a G-protein activating intermediate called metarhodopsin II (Meta-II), where retinal acts as an agonist. G-protein activation efficiency of apoprotein opsin (ligand-free form) is 100 times lower than that of agonist-bound form (Meta-II) in wild type rhodopsin, but that of M257Y opsin is 30 times greater than that of wild type opsin. The high G-protein activation efficiency of CAM opsin can be explained by the altered opsin 
conformation having relatively high Gt activation efficiency, or the generation of small amount of opsin having Meta-II-like conformation in the ensemble ${ }^{11-14}$. While crystal structures of CAMs of rhodopsin in ligand-free form have not been available, previous study on the structural dynamics of CAM of rhodopsin using fluorescence quenching supports the latter ${ }^{10}$. However, it is possible that these two factors synergistically contribute to the constitutive activity. Therefore, direct and quantitative observation of interconversion between active and inactive conformations is essential to address this controversy.

Recently, we have demonstrated that the single-molecule analysis using total internal reflection fluorescence microscopy (TIRFM) is a powerful tool to directly monitor the physiologically relevant conformational changes of rhodopsin ${ }^{15}$. Unlike bulk measurements, single-molecule analysis of individual molecules provides direct information about the duration time in each conformation, and statistical analysis provides information about the kinetics of conformational changes. Here, we labeled M257Y with the Alexa594 fluorophore at Cys316 in the cytoplasmic Helix VIII to probe the conformational change at the single-molecule level. We conducted singlemolecule fluorescence microscopy of Alexa594 in the dark states, photoactivated states, and opsin states (without retinal) of wild type and M257Y to address the mechanism of constitutive activity of opsins and GPCRs. 


\section{MATERIALS AND METHODS}

Sample Preparation. Genes of wild type, C140S (WT $\left.{ }^{\mathrm{C} 140 \mathrm{~S}}\right)$ and C140S/M257Y (M257Y ${ }^{\mathrm{C} 140 \mathrm{~S}}$ ) of bovine rhodopsin were transiently transfected into HEK293T cell lines ${ }^{16-17}$. After collection of cells, pigments were regenerated by adding 11-cis-retinal to the cell membranes. For the singlemolecule fluorescence measurements in the dark state, the pigments were regenerated with nonisomerizable 11-cis-retinal in which $\mathrm{C}_{11}=\mathrm{C}_{12}$ bond is locked in the cis configuration by a 7 membered ring (7m-Ret) to generate fluorescence of Alexa594 without photoreaction of rhodopsin chromophore $^{18-19}$. Pigments were solubilized by OG/asolectin buffer (60 mM n-octyl- $\beta$-Dglucoside, $1 \mathrm{mg} / \mathrm{mL}$ asolectin, $50 \mathrm{mM}$ HEPES, $140 \mathrm{mM} \mathrm{NaCl}$, pH 7.5), and adsorbed to rho1D4 (anti-bovine rhodopsin monoclonal antibody) immunoaffinity beads. After washing with OG/asolectin buffer and labeling buffer (60 mM n-octyl- $\beta$-D-glucoside, $1 \mathrm{mg} / \mathrm{mL}$ asolectin, $5 \mathrm{mM}$ MES, 50 mM HEPES, pH 7.5), 5 times molar excess, over rhodopsin, of Alexa594 maleimide (Molecular Probes) dissolved in DMSO was added to the bead suspension and incubated at $4^{\circ} \mathrm{C}$ overnight. Then the beads were extensively washed by labeling buffer and OG/asolectin buffer, and the labeled pigments were eluted with 8-meric peptide derived from the C-terminal amino acid sequence of bovine rhodopsin. Typically, the molar ratios of pigment and Alexa594 were estimated to be 1:0.9 for $\mathrm{WT}^{\mathrm{C} 140 \mathrm{~S}}$ and 1:1.2 for M257Y $\mathrm{Y}^{\mathrm{C} 140 \mathrm{~S}}$.

To reconstitute the pigments into the liposome, purified pigments in OG/asolectin buffer (molar ratio of pigment and asolectin was 1:1300) were dialyzed against 500 volumes of dialysis buffer (50 mM MES, $140 \mathrm{mM} \mathrm{NaCl}, \mathrm{pH}$ 6.0) at $4{ }^{\circ} \mathrm{C}$ in the dark for $36 \mathrm{~h}$ with six buffer exchanges. Opsin samples were prepared by photobleaching of pigments in the presence of $50 \mathrm{mM}$ hydroxylamine. For control, the $\mathrm{WT}^{\mathrm{C} 140 \mathrm{~S}}$ sample was put onto the boiled water for 5 min to denature rhodopsin. 
$\mathrm{G}$ protein transducin $(\mathrm{Gt})$ was isolated from bovine retinas ${ }^{20-21}$. Rod outer segment membranes isolated from 200 bovine retinas were suspended in ROS buffer (10 mM MOPS, 30 mM NaCl, 60 $\mathrm{mM} \mathrm{KCl,} 2 \mathrm{mM} \mathrm{MgCl}$, $1 \mathrm{mM}$ dithiothreitol, $\mathrm{pH}$ 7.5) and exposed to a fluorescent desk lamp for 30 min so that rhodopsin is converted into Meta-II to form the complex with Gt. After washing the membrane three times with Buffer A (5 mM Tris/ $\mathrm{HCl}, 0.5 \mathrm{mM} \mathrm{MgCl}, 1 \mathrm{mM}$ dithiothreitol, $\mathrm{pH}$ 7.0) containing $0.2 \mathrm{mM}$ EDTA, Gt was released from the membrane by adding Buffer A containing $0.1 \mathrm{mM}$ GTP and the soluble fraction was collected by centrifugation. Extraction by GTP was repeated three times. Gt was further purified by DEAE Toyopearl 650S chromatography (Toso).

Bulk Spectroscopy. UV-visible absorption spectra were recorded using a Shimadzu UV2450 spectrophotometer. Fluorescence time courses were recorded with a Shimadzu RF-5300PC spectrofluorometer. The optical cell holder was temperature-controlled. The sample was irradiated with light generated by a $1 \mathrm{~kW}$ tungsten halogen lamp and passed through a glass cutoff filter (Y52, Toshiba). Fluorescence of Alexa594 was generated by a $590 \mathrm{~nm}$ excitation beam attenuated by a glass cut-off filter (R61, Toshiba) and monitored at $630 \mathrm{~nm}$.

G Protein Activation Aassay. The activation of Gt was assessed by GDP/GTP $\gamma \mathrm{S}$ exchange using a radionucleotide filter-binding assay ${ }^{21}$. All procedures were carried out at $0{ }^{\circ} \mathrm{C}$. Reaction mixtures ( 125 nM pigment, $600 \mathrm{nM} \mathrm{Gt,} 50$ mM MOPS, $140 \mathrm{mM} \mathrm{NaCl,} 2.25 \mathrm{mM} \mathrm{MgCl}$, $1 \mathrm{mM}$ DTT, $2 \mu \mathrm{M}$ GDP, $\mathrm{pH}$ 7.0) were kept in the dark or irradiated with light generated by a $1 \mathrm{~kW}$ tungsten halogen lamp and passed through a Y52 filter for 30 s. The GDP/GTP $\gamma \mathrm{S}$ exchange reaction was then initiated by the addition of $\left[{ }^{35} \mathrm{~S}\right] \mathrm{GTP} \gamma \mathrm{S}$ (final concentration, $1 \mu \mathrm{M}$ ). After 
incubation for a given time in the dark, an aliquot $(20 \mu \mathrm{L})$ of the reaction mixture was mixed with $200 \mu \mathrm{L}$ of stop solution (20 mM Tris/HCl, 100 mM NaCl, 25 mM MgCl $2,1 \mu \mathrm{M}$ GTP $\gamma \mathrm{S}$, and $2 \mu \mathrm{M}$ GDP, pH 7.4), and was immediately filtered through a nitrocellulose membrane to trap [ $\left.{ }^{35} \mathrm{~S}\right] \mathrm{GTP} \gamma \mathrm{S}$ bound to Gt. The amount of bound $\left[{ }^{35} \mathrm{~S}\right] \mathrm{GTP} \gamma \mathrm{S}$ was quantitated by a PerkinElmer Tri-Carb 2910TR liquid scintillation counter.

Single-Molecule Fluorescence Measurements. Just before single-molecule fluorescence measurements, the liposome suspensions containing $\mathrm{WT}^{\mathrm{C} 140 \mathrm{~S}}$ or $\mathrm{M} 257 \mathrm{Y}^{\mathrm{C} 140 \mathrm{~S}}$ were centrifuged to remove aggregates that resulted in very bright fluorescence spots in the TIRFM images. Supernatants were supplemented with 2-mercaptoethanol and Trolox (6-hydroxy-2,5,7,8tetramethylchroman-2-carboxylic acid) at the final concentrations of $0.5 \%(\mathrm{w} / \mathrm{v})$ and $\sim 1 \mathrm{mM}$, respectively, to suppress photobleaching of Alexa594. The supernatants were put into the sample dish with cover glass on the bottom. Fluorescence of Alexa594 adsorbed to the cover glass was observed using the TIRFM composed of an inverted microscope (TE 2000, Nikon) with a 60× oilimmersion objective (ApoTIRF $60 \times 1.49 \mathrm{NA}$, Nikon) $)^{15}$ and $4.0 \times$ relay lens. Fluorescence of Alexa594 was generated by 559-nm laser (WS-0559-050, 50 mW, NTT Electronics). The energy of the laser was reduced by $75 \%$ with neutral density filters. The images were acquired using an EMCCD camera (C9100-13, ImagEM, Hamamatsu) with a 345× EM gain. The $512 \times 512$ pixel images were recorded with a time resolution of 20 frames/s and a magnification of $67 \mathrm{~nm} / \mathrm{pixel}$. The sample dish was maintained at $6^{\circ} \mathrm{C}$ with an air-cooling device (Peltier-4, Taiei Denki). All sample manipulations were performed under dim red light.

Data analyses. Time course of fluorescence intensity was obtained from TIRFM images by using ImageJ. Fluorescence intensity steps were detected by a laboratory-written analytical 
program based on a hidden Markov model ${ }^{22-23}$, developed using LabVIEW software (National Instruments) ${ }^{15}$. All statistical and kinetic analyses were performed with IGOR Pro 6.3 (WaveMetrics). 


\section{RESULTS}

We first optimized the methods to label rhodopsin expressed in the cultured cells with Alexa594, which is sensitive to the conformational changes. In order to exclusively label Cys316 with Alexa594, Cys140 (another chemically modifiable cysteine residue in bovine rhodopsin ${ }^{24}$ ) was replaced by Ser in both the wild type (WT $\left.{ }^{\mathrm{C} 140 \mathrm{~S}}\right)$ and M257Y mutant (M257Y $\left.{ }^{\mathrm{C} 140 \mathrm{~S}}\right)$. Cys316 was labeled with Alexa594 maleimide during the purification using immunoaffinity beads, and these pigments were incorporated into asolectin-liposomes by dialysis.

To assess the impact of C140S mutation, Gt activation efficiency of $\mathrm{WT}^{\mathrm{C} 140 \mathrm{~S}}$ and $\mathrm{M} 257 \mathrm{Y}^{\mathrm{C} 140 \mathrm{~S}}$ was measured by a conventional filter binding assay using radioactive GTP $\gamma \mathrm{S}$ (Figure S1). In the photoactivated state (Meta-II), $\mathrm{WT}^{\mathrm{C} 140 \mathrm{~S}}$ and $\mathrm{M} 257 \mathrm{Y}^{\mathrm{C} 140 \mathrm{~S}}$ exhibited similar and significant GDP/GTP $\gamma \mathrm{S}$ exchange rate. The inverse agonist (11-cis-retinal) suppressed the Gt activation in the dark state. However, in the ligand-free form (opsin), the Gt activation efficiency of M257Y ${ }^{\mathrm{C} 140 \mathrm{~S}}$ was 27-fold greater than that of $\mathrm{WT}^{\mathrm{C} 140 \mathrm{~S}}$. These results were consistent with those of the previous work for wild type and M257Y³.

On irradiation of $\mathrm{WT}^{\mathrm{C} 140 \mathrm{~S}}$, fluorescence of Alexa594 was increased by 30\%, which is derived from the formation of Meta-II in the active (open) conformation (Figure 1a, red). In the presence of hydroxylamine, fluorescence increase was immediately followed by the decrease, indicating that $\mathrm{WT}^{\mathrm{C} 140 \mathrm{~S}}$ opsin is mainly in the inactive (closed) conformation (Figure 1a, blue). However, irradiation of M257Y $\mathrm{Y}^{\mathrm{C} 140 \mathrm{~S}}$ increased fluorescence by only 20\%. Since G-protein activation efficiencies as well as crystal structures of photoactivated states are similar between wild type and M257Y rhodopsin ${ }^{3}$, 9, it is likely that fluorescence intensities of Alexa594 bound to the photoactivated states of $\mathrm{WT}^{\mathrm{C} 140 \mathrm{~S}}$ and $\mathrm{M} 257 \mathrm{Y}^{\mathrm{C} 140 \mathrm{~S}}$ are comparable. Therefore, it is likely that fluorescence intensity of $\mathrm{M} 257 \mathrm{Y}^{\mathrm{C} 140 \mathrm{~S}}$ in the dark state is greater than that of $\mathrm{WT}^{\mathrm{C} 140 \mathrm{~S}}$. This is 
consistent with the finding that the environment around Cys316 in the dark state M257Y is similar to that of Meta-II shown by the EPR experiment using the nitroxide side chain ${ }^{25}$. It should be noted that hydroxylamine did not lower the fluorescence intensity of M257Y ${ }^{\mathrm{C} 140 \mathrm{~S}}$ (Figure 1a), indicating that the fluorescence intensity of M257Y $\mathrm{Y}^{\mathrm{C} 140 \mathrm{~S}}$ opsin was greater than that of $\mathrm{WT}^{\mathrm{C} 140 \mathrm{~S}}$ opsin.

Next, the TIRFM images of liposomes containing Alexa594-labeled WT ${ }^{\mathrm{C} 140 \mathrm{~S}}$ or M257Y ${ }^{\mathrm{C} 140 \mathrm{~S}}$ were recorded every $50 \mathrm{~ms}$, which clearly showed relatively uniform fluorescence spots (Figure 1b). The fluorescence intensity of each spot was determined by calculating the average intensity of $12 \times 12$ pixel region. The fluorescence time course of each spot is shown by plotting the fluorescence intensity against time (Figure 1c), and the histograms of maximal fluorescence intensity of the spots were constructed (Figure S2). They were fitted with the sum of two Gaussian functions assuming that the fluorescence spots contain one or two Alexa594 molecules ${ }^{15}$ (Eq. S1), where $\sim 90 \%$ of spots were derived from a single Alexa594 molecule. To exclude the fluorescence spots containing two or more Alexa594-labeled rhodopsin molecules, the fluorescence spots whose intensity is within the full width at half maximum of the main distribution (intensity of a single Alexa594 molecule, blue thick line in Figure S2) were subjected to further analysis.

In the time course of the fluorescence intensity (Figure 1c), both $\mathrm{WT}^{\mathrm{C} 140 \mathrm{~S}}$ and $\mathrm{M} 257 \mathrm{Y}^{\mathrm{C} 140 \mathrm{~S}}$ showed stepwise fluorescence changes between high-fluorescence state $\left(F_{\text {high }}\right)$ and lowfluorescence state $\left(\mathrm{F}_{\text {low }}\right)$, and eventual fluorescence decrease to zero derived from bleaching of Alexa594. The fluorescence change points were detected using laboratory-developed program based on the hidden Markov model (Figure 1c, smooth orange/magenta/cyan lines) ${ }^{15,22-23}$. We first analyzed the frequency and amplitude of conversion between $F_{\text {high }}$ and $F_{\text {low }}$ (Figure 1c, orange). The histograms for the change in the fluorescence intensity $(\Delta I)$, which was normalized relative to 
the maximal fluorescence intensity of each spot, are constructed for dark states, photoactivated states, and opsins (Figures 2a and 2b). For the measurements in the dark state, the pigments were regenerated with 11 -cis-locked retinal ${ }^{15,18}$, and the photoactivated state mostly contained Meta-II at $\mathrm{pH}$ 6.0. Opsin samples were prepared by photobleaching of pigments in the presence of $50 \mathrm{mM}$ hydroxylamine. As a control experiment, the same measurements and analyses were carried out using $\mathrm{WT}^{\mathrm{C} 140 \mathrm{~S}}$ samples denatured by boiling (Figure 2c). The histogram of the denatured sample was fitted with a mirror-imaged distribution, whereas that of photoactivated state was broad and fitted with the combination of two sets of mirror-imaged distributions. The mirror-imaged distribution observed in the denatured sample reflects a noise component (NC, blue line) derived from the false-detection of fluorescence change points in our experimental setup and/or analytical algorithm $^{15}$. Another distribution observed in the photoactivated sample shows the signal component (SC, green line) derived from the conformational switch between $\mathrm{F}_{\text {low }}$ and $\mathrm{F}_{\text {high. }}$ Assuming that NC was included regardless of the state of the sample, all the histograms in Figure 2 were global-fitted with the combination of mirror-imaged normal distribution for SC and lognormal distribution for NC (Eq. S2), where the parameters for the NC were global (Supporting Information).

In addition to the photoactivated state, SC was observed in opsin, where SC of M257Y ${ }^{\mathrm{C} 140 \mathrm{~S}}$ was greater than that of $\mathrm{WT}^{\mathrm{C} 140 \mathrm{~S}}$ (Figures 2a and $2 \mathrm{~b}$ ). It is consistent with the previous study that M257Y mutation lowered the energy barrier between inactive and active conformation of opsin ${ }^{10}$. In Figure 2d, the amplitudes of SC of the dark states, photoactivated states, and opsins of $\mathrm{WT}^{\mathrm{C} 140 \mathrm{~S}}$ and $\mathrm{M} 257 \mathrm{Y}^{\mathrm{C} 140 \mathrm{~S}}$ were compared. Fluorescence changes in $\mathrm{M} 257 \mathrm{Y}^{\mathrm{C} 140 \mathrm{~S}}$ opsin occurred more frequently than in $\mathrm{WT}^{\mathrm{C} 140 \mathrm{~S}}$ opsin, while the difference between $\mathrm{WT}^{\mathrm{C} 140 \mathrm{~S}}$ and M257Y $\mathrm{Y}^{\mathrm{C} 140 \mathrm{~S}}$ was not significant in photoactivated state. In $\mathrm{M} 257 \mathrm{Y}^{\mathrm{C} 140 \mathrm{~S}}$, frequencies of fluorescence changes in 
photoactivated state and opsin were comparable, which was consistent with the bulk fluorescence measurement (Figure 1a). It should be noted that a small distribution of SC was also observed for the dark state of M257Y $\mathrm{Y}^{\mathrm{C} 140 \mathrm{~S}}$.

Figure $2 d$ suggests that conformational dynamics in opsin state is notably affected by CAM. To assess the kinetics of the conformational change, the histograms of the probability distribution of duration times in $F_{\text {high }}$ (Figure 1c, magenta) and $F_{\text {low }}$ (Figure 1c, cyan) were constructed for photoactivated states and opsin states $\left(f_{\text {high } \rightarrow \text { low }}(t)\right.$ and $f_{\text {low } \rightarrow \text { high }}(t)$ in Figures 3a-3d, respectively). In addition, the histograms $\left(f_{\text {high } \rightarrow \text { low }}(t)\right.$ and $f_{\text {low } \rightarrow \text { high }}(t)$ of the denatured sample was also constructed to examine the kinetics of fluorescence changes by NC (Figure 3e). While it is essential to compare the kinetic parameters of interconversion between $\mathrm{F}_{\text {high }}$ and $\mathrm{F}_{\text {low }}$ in $\mathrm{WT}^{\mathrm{C} 140 \mathrm{~S}}$ opsin and M257Y $\mathrm{Y}^{\mathrm{C} 140 \mathrm{~S}}$ opsin, it was difficult to estimate the rate constants of SC from the duration time histograms because significant amount of fluorescence changes was derived from NC in opsin states (Figures 2a and $2 \mathrm{~b})$. This means that the probability distribution of duration times is the sum of exponential functions expressing the interconversion between $F_{\text {high }}$ and $F_{\text {low }}(\mathrm{SC})$ and false detection (NC), where the latter is significantly greater than the former. To analyze the kinetics involving SC and NC, we generated an equilibrium model in which $F_{\text {high }}$ and $F_{\text {low }}$ are composed of two substates showing relatively high and low fluorescence intensity $\left(\mathbf{H}\right.$ and $\mathbf{H}^{\prime}$ for $F_{\text {high }}$ and $\mathbf{L}$ and $\mathbf{L}$ ' for Flow, respectively) (Figure S3). In the denatured sample, fluorescence changes are derived only from NC between $\mathbf{D}$ and $\mathbf{D}^{\prime}$. In this scheme, the fluorescence conversions for $\mathbf{H} \leftrightarrow \mathbf{H}^{\prime}, \mathbf{L} \leftrightarrow \mathbf{L}$, and $\mathbf{D}$ $\leftrightarrow$ D' are assumed to be derived from stochastic false detections (NC) (Supporting Information). Based on this model, the probability distributions of duration times before fluorescence decrease $\left(f_{\text {high } \rightarrow \text { low }}(t)\right)$ or increase $\left(f_{\text {low } \rightarrow \text { high }}(t)\right)$ were expressed using the rate constants for SC and NC (Eqs. S30-S33). Using these equations, the duration time histograms were global-fitted (Figure 3 and 
Table S1). This analysis was validated by calculating the ratio of SC and NC using these rate constants, which agreed with the ratio of SC and NC in difference intensity histogram (Figure 2) (Figure S4 and Table S2).

The rate constants of conformational change from $F_{\text {high }}$ to $F_{\text {low }}\left(k_{\mathrm{s} 1}\right)$ and that from $F_{\text {low }}$ to $F_{\text {high }}$ $\left(k_{\mathrm{s} 2}\right)$ are shown in Figure 3f. The $k_{\mathrm{S} 2}$ of $\mathrm{M} 257 \mathrm{Y}^{\mathrm{C} 140 \mathrm{~S}}$ opsin $\left(0.42 \mathrm{~s}^{-1}\right)$ was about seven times greater than that of $\mathrm{WT}^{\mathrm{C} 140 \mathrm{~S}}$ opsin $\left(0.06 \mathrm{~s}^{-1}\right)$, while difference in $k_{\mathrm{S} 1}$ of the two was relatively small $(0.38$ and $0.99 \mathrm{~s}^{-1}$ ). These results imply that the population of active state of $\mathrm{M} 257 \mathrm{Y}^{\mathrm{C} 140 \mathrm{~S}}$ opsin is increased mainly by the frequent formation of active conformation $\left(F_{\text {high }}\right)$, rather than the stabilization of active conformation. The fraction of $F_{\text {high }}$ was calculated to be 0.521 and 0.056 for M257Y $\mathrm{Y}^{\mathrm{C} 140 \mathrm{~S}}$ opsin and $\mathrm{WT}^{\mathrm{C} 140 \mathrm{~S}}$ opsin, respectively, implying that M257Y mutation causes the decrease in $\Delta G$ between $\mathrm{F}_{\text {low }}$ and $\mathrm{F}_{\text {high }}$ by $8.2 \mathrm{~kJ} / \mathrm{M}$. This population shift ( $\sim 10$ times) is consistent with the difference in Gt activation efficiency between WT opsin and M257Y opsin ${ }^{3}$, while it is different from the results of previous bulk fluorescence measurement in which M257Y mutation does not significantly alter the stable population of active conformation of opsin in nanodiscs ${ }^{10}$. 


\section{DISCUSSION}

We have previously shown that light-induced generation of the active conformation of rhodopsin could be monitored at the single-molecule level by measuring the fluorescence of Alexa594 immobilized at Cys316. The inverse agonist (11-cis-retinal) shifts the equilibrium toward the inactive conformation, whereas the agonist (unprotonated all-trans-retinal) shifts it toward the active conformation ${ }^{15}$. A similar observation has been reported for $\beta_{2}$-adrenergic receptor, a typical GPCR, in which conformational equilibria between active and inactive states are modulated by the species of diffusible ligands ${ }^{26}$. Here, this concept was extended to constitutive activity of ligand-free opsin.

While previous studies have shown that wild type opsin forms Meta-II-like conformation at acidic $\mathrm{pH}^{27}$, our single-molecule observation directly detected the formation of Meta-II-like conformation of opsin at physiologic $\mathrm{pH}^{15}$, where Meta-II-like conformation is minor. By using this technique, we successfully showed that conformational changes occurred more frequently in M257Y $\mathrm{Y}^{\mathrm{C} 140 \mathrm{~S}}$ opsin (CAM) than in $\mathrm{WT}^{\mathrm{C} 140 \mathrm{~S}}$ opsin. In addition, our kinetic analysis found that the elevated rate constant of the conversion from inactive to active conformation ( $F_{\text {low }}$ to $F_{\text {high }}$ ) results in the shift of conformational equilibrium toward the active state in CAM. Quantitative agreement between this population shift ( 10 times) and the difference in Gt activation efficiency between WT opsin and M257Y opsin ( 30 times) implies that the constitutive activity is mainly accounted for by the population shift mechanism, which is essentially similar to the ligand-induced activation of native rhodopsin in which the frequent generation of active conformation in Meta-II state results in the accumulation of active conformation ${ }^{15}$ (Figure 4). It should be noted that although the Gprotein activation in the dark state of M257Y was not detected, infrequent generation of Fhigh was observed in our single-molecule measurements. This discrepancy might be derived from the 
position of fluorescent Alexa594 which reports the conformational changes. Although Alexa594 bound to Cys316 on helix VIII is sensitive to the environmental change caused by rhodopsin activation $^{28}$, this site is distant from TM6 ${ }^{10,29}$, major site of conformational change.

When light is absorbed by the visual pigments in the cells, visual pigments are bleached to form opsins. Constitutive activity of opsin causes the elevation of the background level of Gt activation. This phenomenon is called bleaching adaptation, and results in the desensitization of the cell. Therefore, constitutive activity of opsin should be lowered to improve the photosensitivity of the visual cells. In addition, M257Y has the ability to take up all-trans-retinal as an exogenous ligand to activate $\mathrm{Gt}^{3,8}$. Met257, which is widely conserved in rhodopsins as well as in cone visual pigments, suppresses not only the constitutive activity but also the uptake of the agonist all-transretinal by modulating the conformational dynamics, which is essential to lower the dark noise.

It is established that vertebrate rhodopsin has two major ionic locks that maintain inactive conformation in the dark state ${ }^{30}$. One is between the protonated Schiff base of the chromophore and counterion Glu113, and the other is between cytoplasmic Arg135 and Glu247. In opsin, the chromophore ionic lock is replaced by the salt bridge between Glu113 and Lys296. Since perturbation of the cytoplasmic ionic lock by M257Y mutation dramatically alters both the Gprotein activation efficiency and conformational dynamics in ligand-free opsin state, the cytoplasmic ionic lock would be strongly coupled with Glu113-Lys296 ionic lock in opsin. M257Y mutation would disrupt Glu113-Lys296 ionic lock and destabilize the inactive form, resulting in the ready generation of active conformation (Figure 4).

CONCLUSION 
The constitutive activity of M257Y opsin is explained by the shift in conformational equilibrium toward the active conformation. It is essentially consistent with the ligand-induced activations of GPCRs $^{15,26}$, indicating that both the constitutive activity and ligand-induced activity of GPCRs are understood in the same framework of population shift (Figure 4). Since CAM of GPCRs often causes diseases, our findings suggested that dysregulation of protein dynamics has a direct connection to diseases development. 


\section{ASSOCIATED CONTENT}

\section{Supporting Information.}

The Supporting Information is available free of charge on the ACS Publications website.

Characterization of $\mathrm{WT}^{\mathrm{C} 140 \mathrm{~S}}$ and $\mathrm{M} 257 \mathrm{Y}^{\mathrm{C} 140 \mathrm{~S}}$; Fluorescence intensity of each fluorescent spot in single-molecule images; analysis of the frequency of fluorescence changes; kinetic analysis; validation of the kinetic analysis (PDF).

\section{AUTHOR INFORMATION}

\section{*Corresponding Author}

e-mail: imamoto@rh.biophys.kyoto-u.ac.jp

\section{Notes}

The authors declare no competing financial interest.

\section{ACKNOWLEDGMENTS}

We are grateful to Prof. Robert S. Molday of the University of British Columbia for providing the hybridoma that produces rho1D4 antibody. This work was supported by JSPS KAKENHI Grant Numbers JP16K07319 and JP16H02515. 


\section{REFERENCES}

(1) Robinson, P. R.; Cohen, G. B.; Zhukovsky, E. A.; Oprian, D. D. Constitutively active mutants of rhodopsin. Neuron 1992, 9, 719-725.

(2) Cohen, G. B.; Yang, T.; Robinson, P. R.; Oprian, D. D. Constitutive activation of opsin: influence of charge at position 134 and size at position 296. Biochemistry 1993, 32, 6111-6115.

(3) Han, M.; Smith, S. O.; Sakmar, T. P. Constitutive activation of opsin by mutation of methionine 257 on transmembrane helix 6. Biochemistry 1998, 37, 8253-8261.

(4) Dryja, T. P.; Berson, E. L.; Rao, V. R.; Oprian, D. D. Heterozygous missense mutation in the rhodopsin gene as a cause of congenital stationary night blindness. Nature genetics 1993, 4, 280283.

(5) Rao, V. R.; Cohen, G. B.; Oprian, D. D. Rhodopsin mutation G90D and a molecular mechanism for congenital night blindness. Nature 1994, 367, 639-642.

(6) Gross, A. K.; Rao, V. R.; Oprian, D. D. Characterization of rhodopsin congenital night blindness mutant T94I. Biochemistry 2003, 42, 2009-2015.

(7) Tao, Y. X. Constitutive activation of G protein-coupled receptors and diseases: insights into mechanisms of activation and therapeutics. Pharmacology \& therapeutics 2008, 120, 129-148.

(8) Schafer, C. T.; Farrens, D. L. Conformational selection and equilibrium governs the ability of retinals to bind opsin. J. Biol. Chem. 2015, 290, 4304-4318.

(9) Deupi, X.; Edwards, P.; Singhal, A.; Nickle, B.; Oprian, D.; Schertler, G.; Standfuss, J. Stabilized G protein binding site in the structure of constitutively active metarhodopsin-II. Proc. Natl. Acad. Sci. U. S. A. 2012, 109, 119-124. 
(10) Tsukamoto, H.; Farrens, D. L. A constitutively activating mutation alters the dynamics and energetics of a key conformational change in a ligand-free G protein-coupled receptor. J Biol Chem 2013, 288, 28207-28216.

(11) Samama, P.; Cotecchia, S.; Costa, T.; Lefkowitz, R. J. A mutation-induced activated state of the $\beta_{2}$-adrenergic receptor. Extending the ternary complex model. J. Biol. Chem. 1993, 268, 4625-4636.

(12) Lefkowitz, R. J.; Cotecchia, S.; Samama, P.; Costa, T. Constitutive activity of receptors coupled to guanine nucleotide regulatory proteins. Trends Pharmacol. Sci. 1993, 14, 303-307.

(13) Robertson, M. J.; Dougall, I. G.; Harper, D.; McKechnie, K. C.; Leff, P. Agonist-antagonist interactions at angiotensin receptors: application of a two-state receptor model. Trends Pharmacol. Sci. 1994, 15, 364-369.

(14) Leff, P. The two-state model of receptor activation. Trends Pharmacol. Sci. 1995, 16, 8997.

(15) Maeda, R.; Hiroshima, M.; Yamashita, T.; Wada, A.; Nishimura, S.; Sako, Y.; Shichida, Y.; Imamoto, Y. Single-molecule observation of the ligand-induced population shift of rhodopsin, a G-protein-coupled receptor. Biophys. J. 2014, 106, 915-924.

(16) Nathans, J. Determinants of visual pigment absorbance: role of charged amino acids in the putative transmembrane segments. Biochemistry 1990, 29, 937-942.

(17) Imai, H.; Terakita, A.; Shichida, Y. Analysis of amino acid residues in rhodopsin and cone visual pigments that determine their molecular properties. Methods Enzymol. 2000, 315, 293-312. 
(18) Akita, H.; Tanis, S. P.; Adams, M.; Baloghnair, V.; Nakanishi, K. Non-bleachable rhodopsins retaining the full natural chromophore. J. Am. Chem. Soc. 1980, 102, 6370-6372.

(19) Mao, B.; Tsuda, M.; Ebrey, T. G.; Akita, H.; Balogh-Nair, V.; Nakanishi, K. Flash photolysis and low temperature photochemistry of bovine rhodopsin with a fixed 11-ene. Biophys. J. 1981, 35, 543-546.

(20) Tachibanaki, S.; Imai, H.; Mizukami, T.; Okada, T.; Imamoto, Y.; Matsuda, T.; Fukada, Y.; Terakita, A.; Shichida, Y. Presence of two rhodopsin intermediates responsible for transducin activation. Biochemistry 1997, 36, 14173-14180.

(21) Yamashita, T.; Terakita, A.; Shichida, Y. Distinct roles of the second and third cytoplasmic loops of bovine rhodopsin in G protein activation. J. Biol. Chem. 2000, 275, 34272-34279.

(22) Rabiner, L. R. A Tutorial on Hidden Markov Models and Seleceted Applications in Speech Recognition. Proce. IEEE 1989, 77, 257-286.

(23) Bronson, J. E.; Fei, J.; Hofman, J. M.; Gonzalez, R. L., Jr.; Wiggins, C. H. Learning rates and states from biophysical time series: a Bayesian approach to model selection and singlemolecule FRET data. Biophys. J. 2009, 97, 3196-3205.

(24) Imamoto, Y.; Kataoka, M.; Tokunaga, F.; Palczewski, K. Light-induced conformational changes of rhodopsin probed by fluorescent Alexa594 immobilized on the cytoplasmic surface. Biochemistry 2000, 39, 15225-15233.

(25) Kim, J. M.; Altenbach, C.; Kono, M.; Oprian, D. D.; Hubbell, W. L.; Khorana, H. G. Structural origins of constitutive activation in rhodopsin: Role of the K296/E113 salt bridge. Proc. Natl. Acad. Sci. U. S. A. 2004, 101, 12508-12513. 
(26) Lamichhane, R.; Liu, J. J.; Pljevaljcic, G.; White, K. L.; van der Schans, E.; Katritch, V.; Stevens, R. C.; Wüthrich, K.; Millar, D. P. Single-molecule view of basal activity and activation mechanisms of the G protein-coupled receptor $\beta_{2}$ AR. Proc. Natl. Acad. Sci. U. S. A. 2015, 112, 14254-14259.

(27) Vogel, R.; Siebert, F. Conformations of the active and inactive states of opsin. J. Biol. Chem. 2001, 276, 38487-38493.

(28) Altenbach, C.; Kusnetzow, A. K.; Ernst, O. P.; Hofmann, K. P.; Hubbell, W. L. Highresolution distance mapping in rhodopsin reveals the pattern of helix movement due to activation. Proc. Natl. Acad. Sci. U. S. A. 2008, 105, 7439-7444.

(29) Farrens, D. L.; Altenbach, C.; Yang, K.; Hubbell, W. L.; Khorana, H. G. Requirement of rigid-body motion of transmembrane helices for light activation of rhodopsin. Science 1996, 274, 768-770.

(30) Vogel, R.; Sakmar, T. P.; Sheves, M.; Siebert, F. Coupling of protonation switches during rhodopsin activation. Photochem. Photobiol. 2007, 83, 286-292. 

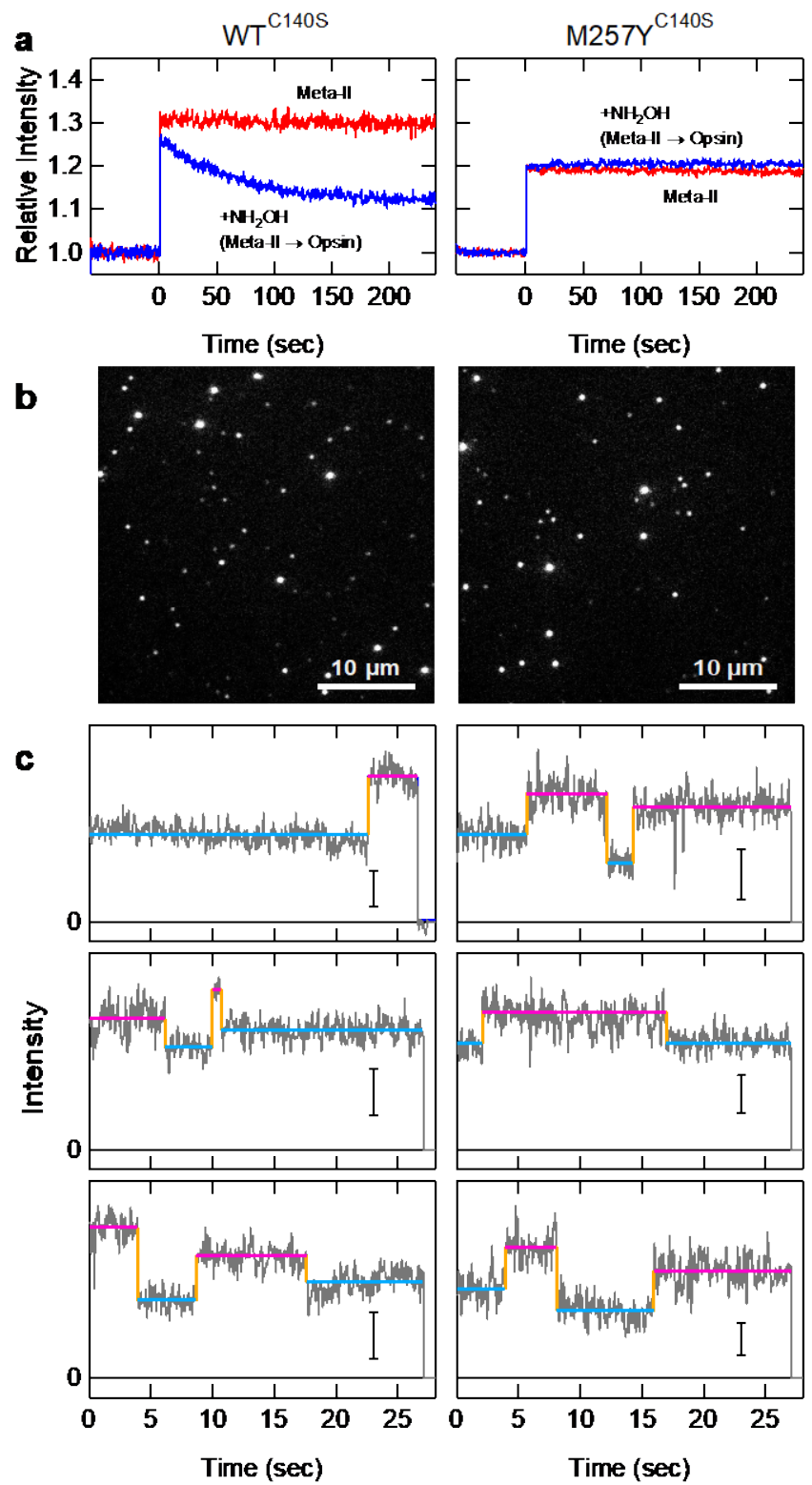

Figure 1. Fluorescence measurements of Alexa594 immobilized at Cys316. (a) Bulk fluorescence measurements of $\mathrm{WT}^{\mathrm{C} 140 \mathrm{~S}}$ (left) and $\mathrm{M} 257 \mathrm{Y}^{\mathrm{C} 140 \mathrm{~S}}$ (right). Photoactivation of $\mathrm{WT}^{\mathrm{C} 140 \mathrm{~S}}$ and $\mathrm{M} 257 \mathrm{Y}^{\mathrm{C} 140 \mathrm{~S}}$ at $t=0$ generated Meta-II, which shows fluorescence increase (red). In the presence of $50 \mathrm{mM}$ hydroxylamine, Meta-II decayed to opsin (blue). It should be noted that fluorescence intensity of $\mathrm{WT}^{\mathrm{C} 140 \mathrm{~S}}$ opsin was smaller than Meta-II, while that of M257Y $\mathrm{Y}^{\mathrm{C} 140 \mathrm{~S}}$ opsin was comparable to Meta-II. (b) The TIRFM image of liposomes containing $\mathrm{WT}^{\mathrm{C} 140 \mathrm{~S}}$ (left) or M257Y $\mathrm{Y}^{\mathrm{C} 140 \mathrm{~S}}$ (right) opsin (pH 6.0). (c) Typical time courses of fluorescence intensity of $\mathrm{WT}^{\mathrm{C} 140 \mathrm{~S}}$ 
(left) and $\mathrm{M} 257 \mathrm{Y}^{\mathrm{C} 140 \mathrm{~S}}$ opsin (right) at $\mathrm{pH}$ 6.0. Fluorescence change points were detected by using a laboratory-written analytical program based on a hidden Markov model (smooth orange/magenta/cyan lines). Intensity change at fluorescence change point ( $\Delta I$, orange) and duration times of high fluorescence state ( $F_{\text {high }}$, magenta) and low fluorescence state ( $F_{\text {low }}$, cyan) were analyzed (Figures 2 and 3, respectively). 

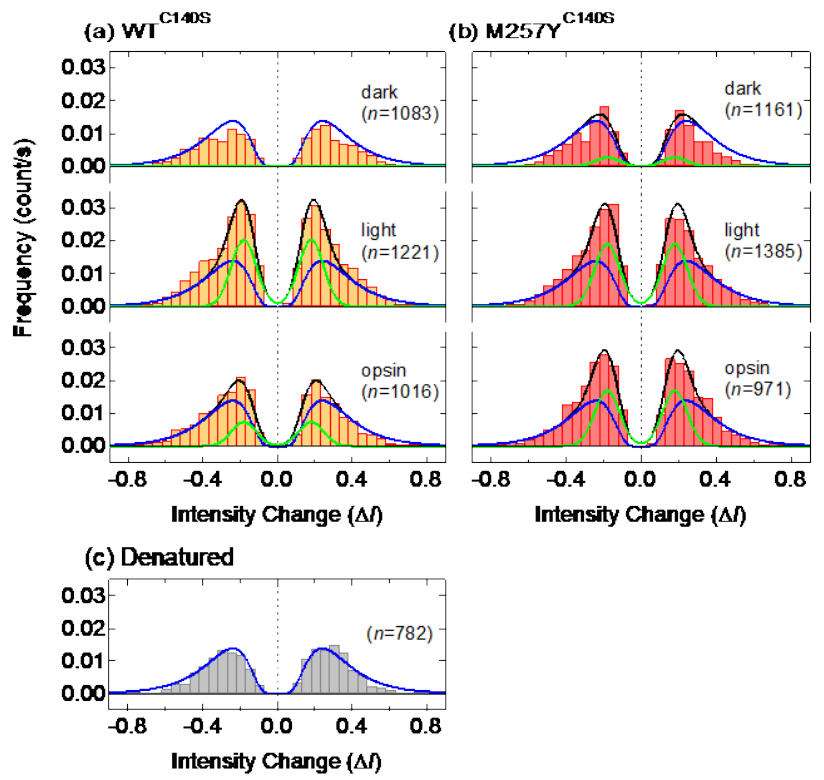

(d)

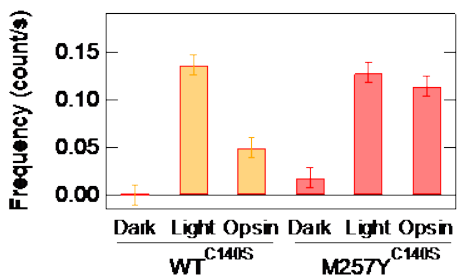

Figure 2. The amplitude and frequency of fluorescence changes. (a-c) The histograms of difference in fluorescence intensity at the change points ( $\Delta I$, orange lines in Figure $1 c)$ in the dark state (dark), photoactivated state (light), and opsin (opsin) for $\mathrm{WT}^{\mathrm{C} 140 \mathrm{~S}}$ (a) and $\mathrm{M}^{257 \mathrm{Y}^{\mathrm{C} 140 \mathrm{~S}}}$ (b). The histogram for the denatured sample is also shown for comparison (c). Green and blue curves show signal components (SC) and noise components (NC), respectively, and black curves show the sum of SC and NC. (d) Frequency of the conformational change derived from the SC. 

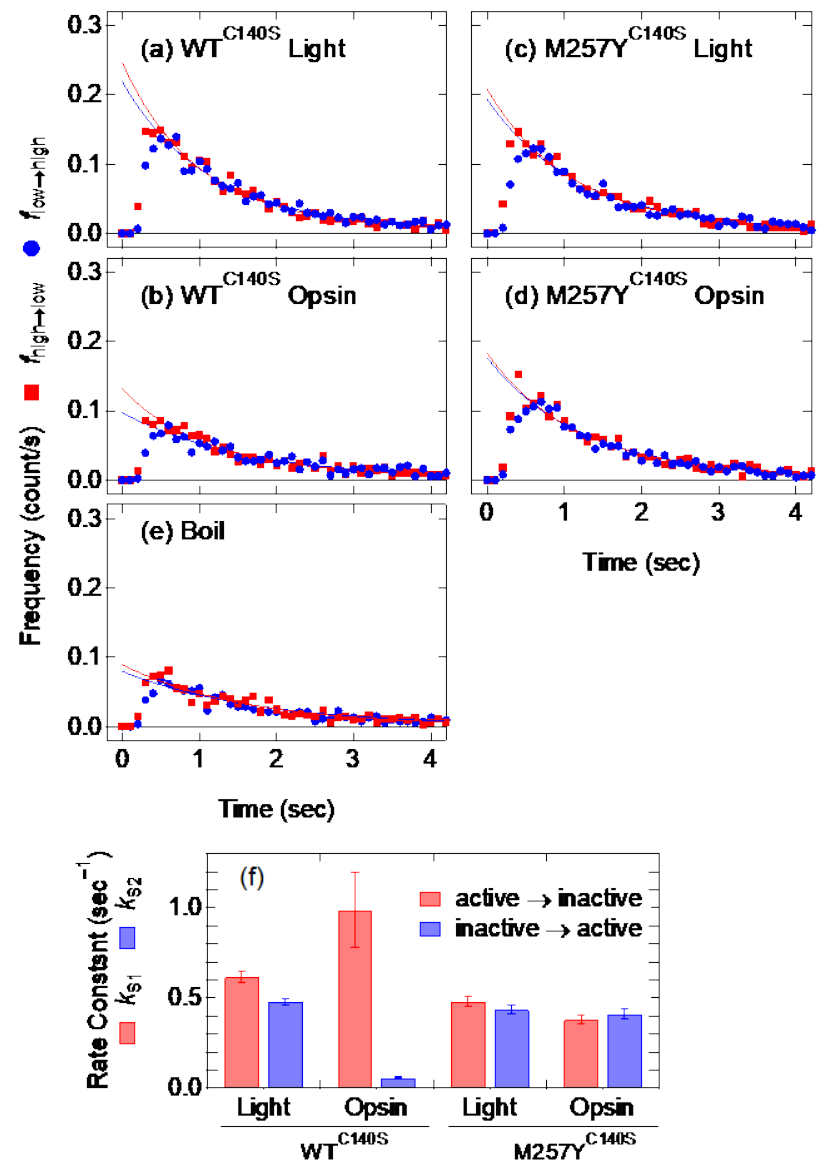

Figure 3. Histograms of duration times of $F_{\text {high }}$ and $F_{\text {low. }}$ (a-e) Histograms of duration time $F_{\text {high }}$ (magenta in Figure 1c) and $F_{\text {low }}$ (cyan in Figure 1c) were constructed for photoactivated state and opsin of WT $\mathrm{W}^{\mathrm{C} 140 \mathrm{~S}}$ and M257Y $\mathrm{Y}^{\mathrm{C} 140 \mathrm{~S}}$ (a-d) or boiled sample (e). (f) Rate constants for SC from Fhigh to $\mathrm{F}_{\text {low }}\left(k_{\mathrm{s} 1}\right.$, red) and those from $\mathrm{F}_{\text {low }}$ to $\mathrm{F}_{\text {high }}\left(k_{\mathrm{s} 2}\right.$, blue) for photoactivated state (light) and opsin were estimated by global fitting (Supporting Information). Error bar indicates the standard deviation of curve fitting. 


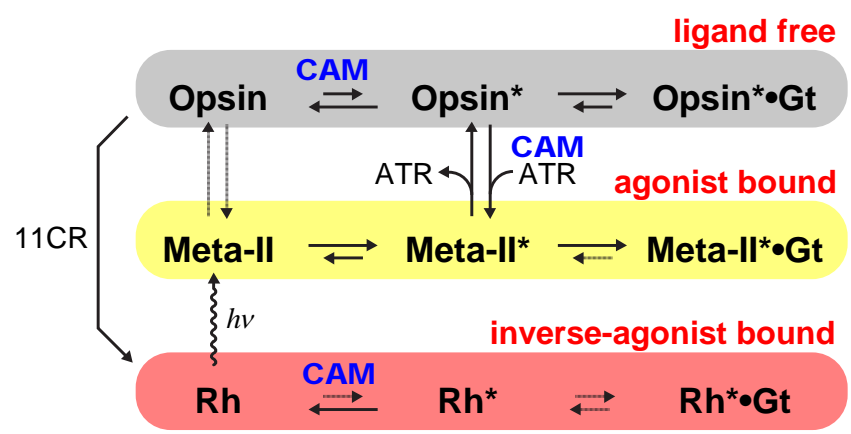

Figure 4. Population shift model for constitutive activity of rhodopsin. (Gray) In ligand free opsin, M257Y mutation shifts the conformational equilibrium towards the active form (Opsin*) by elevating the rate constant for formation of Opsin*. It has been reported that M257Y can pick up all-trans-retinal (ATR) as the exogenous ligand ${ }^{3,8}$ to form Meta-II*. (Yellow) In agonist bound form (Meta-II), effect of CAM on the conformational equilibrium was not observed. (Red) In the dark state, infrequent formation of $\mathrm{Rh}^{*}$ was observed in M257Y, while it was not sufficient to activate G-proteins. This mechanism would be applicable for general GPCRs which are activated by diffusible ligands. 
TOC Graphics

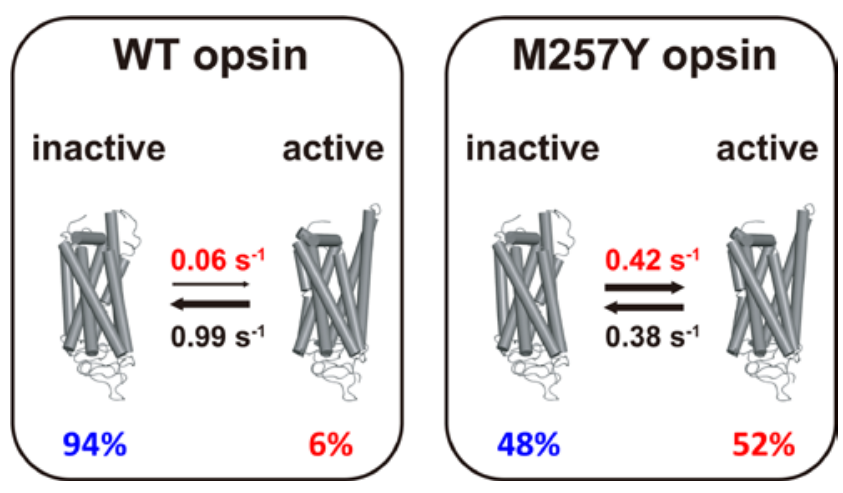




\section{SUPPORTING INFORMATION}

\section{Shift in Conformational Equilibrium Induces Constitutive Activity of G-Protein-Coupled Receptor, Rhodopsin}

Ryo Maeda, ${ }^{\dagger \neq}$ Michio Hiroshima, ${ }^{\ddagger, \|}$ Takahiro Yamashita, ${ }^{\dagger}$ Akimori Wada, ${ }^{\S}$ Yasushi Sako, ${ }^{\ddagger}$ Yoshinori Shichida, ${ }^{\dagger, \perp}$ and Yasushi Imamoto ${ }^{*}, \dagger$

${ }^{\dagger}$ Department of Biophysics, Graduate School of Science, Kyoto University, Kyoto, Japan,

${ }^{\ddagger}$ Cellular Informatics Laboratory, RIKEN, Wako, Saitama, Japan

"Laboratory for Cell Signaling Dynamics, RIKEN Quantitative Biology Center, Suita, Osaka, Japan

${ }^{\S}$ Laboratory of Organic Chemistry for Life Science, Kobe Pharmaceutical University, Kobe, Hyogo, Japan

${ }^{\perp}$ Research Organization for Science and Technology, Ritsumeikan University, Kusatsu, Shiga, Japan

${ }^{*}$ Corresponding Author

\section{RESULTS}

Characterization of $\mathbf{W T}^{\mathrm{C} 140 \mathrm{~S}}$ and $\mathbf{M} 257 \mathrm{Y}^{\mathrm{C} 140 \mathrm{~S}}$. G protein transducin (Gt) activation efficiency of $\mathrm{WT}^{\mathrm{C} 140 \mathrm{~S}}$ and $\mathrm{M} 257 \mathrm{Y}^{\mathrm{C} 140 \mathrm{~S}}$ was measured by a conventional filter binding assay using radioactive GTP $\gamma \mathrm{S}$ (Figure S1). In the photoactivated state (Meta-II), $\mathrm{WT}^{\mathrm{C} 140 \mathrm{~S}}$ and $\mathrm{M} 257 \mathrm{Y}^{\mathrm{C} 140 \mathrm{~S}}$ exhibited similar and significant GDP/GTP $\gamma$ S exchange rate. The inverse agonist (11-cis-retinal) suppressed the Gt activation in the dark state.

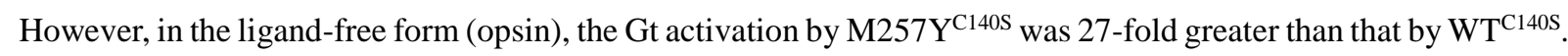
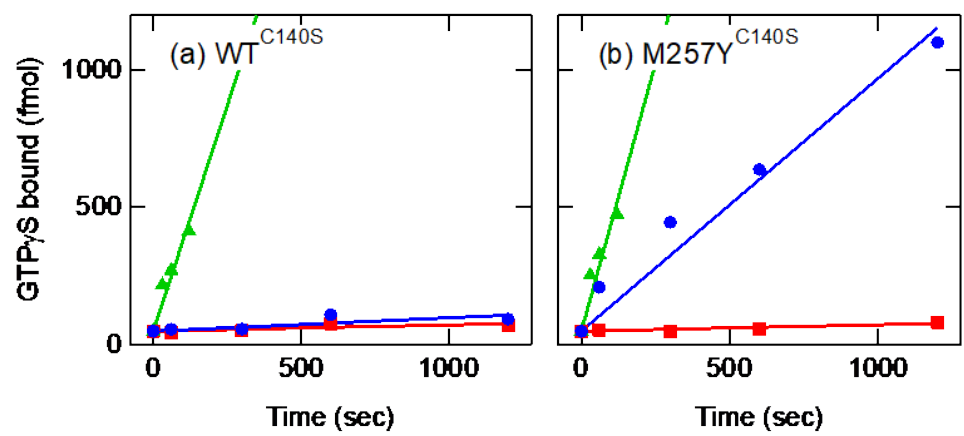

Figure S1. Characterization of $\mathrm{WT}^{\mathrm{C} 140 \mathrm{~S}}$ and $\mathrm{M} 257 \mathrm{Y}^{\mathrm{C} 140 \mathrm{~S}}$. Gt activation efficiency of $\mathrm{WT}^{\mathrm{C} 140 \mathrm{~S}}$ (a) and $\mathrm{M} 257 \mathrm{Y}^{\mathrm{C} 140 \mathrm{~S}}$ (b) in the dark state (red square), photoactivated state (green triangle), and opsin (blue circle) were measured by filter binding assay. 
Fluorescence Intensity of Each Fluorescent Spot in Single-Molecule Images. In order to estimate the number of Alexa594 molecule(s) in each fluorescent spot in single-molecule images, the histograms of maximal fluorescence intensity of the spots were constructed (Figure S2). They were fitted with the sum of two Gaussian functions assuming that the spots contain one or two Alexa594 molecule(s) as follows:

$$
A(I)=A_{1} e^{-\frac{(I-\mu)^{2}}{2 \sigma^{2}}}+A_{2} e^{-\frac{(I-2 \mu)^{2}}{4 \sigma^{2}}}
$$

where $I$ is the maximum fluorescence intensity of each spot, $\mu$ is the mean intensity for a single Alexa594 molecule, $A_{i}(i=1,2)$ is the frequency at $i \mu$, and $i \sigma^{2}$ is the variance of each distribution. The fluorescence spots whose intensities were within the full width at half maximum of the main distribution (mean intensity $=\mu$, blue thick lines), were subjected to further analysis. Within this range, $\sim 90 \%$ of fluorescent spots were derived from a single Alexa594 molecule.
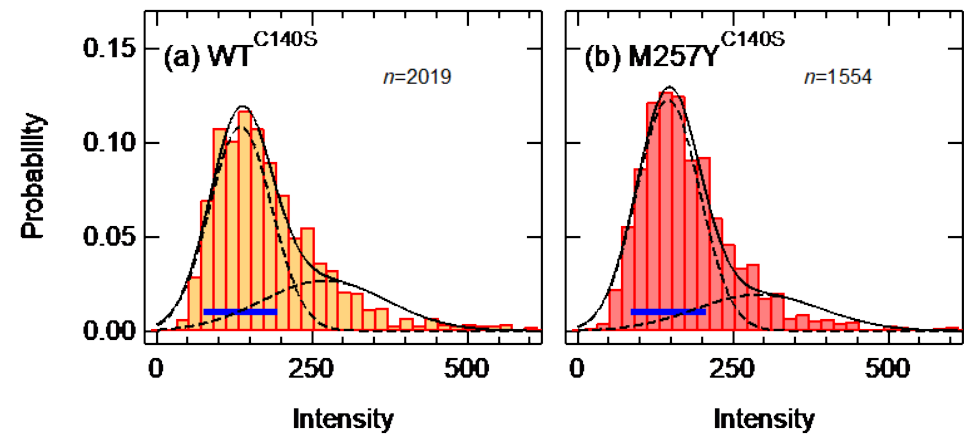

Figure S2. The histogram of maximal fluorescence intensity of $\mathrm{WT}^{\mathrm{C} 140 \mathrm{~S}}$ (a) or M257Y $\mathrm{Y}^{\mathrm{C} 140 \mathrm{~S}}$ (b) in photoactivated state ( $\mathrm{pH}$ 6.0). Blue thick lines indicate the full width at half maximum of the Gaussian distribution for the fluorescence intensity of a single Alexa594 molecule.

Analysis of the Frequency of Fluorescence Changes. In order to analyze the fluorescence changes in single-molecule measurements, the histograms for the change in the fluorescence intensity $(\Delta I)$, which was normalized relative to the maximal fluorescence intensity of each spot, are constructed for dark states, photoactivated states, and opsins (Figures 2a and 2b). As a control experiment, the same measurements and analyses were carried out using $\mathrm{WT}^{\mathrm{C} 140 \mathrm{~S}}$ samples denatured by boiling (Figure 2c). Because better fitting results were obtained when lognormal distribution rather than normal distribution was used for noise component (NC) ( $\chi^{2}=0.000684$ or 0.000718 , respectively), all the histograms in Figure 2 were fitted with the combination of mirror-imaged normal distribution for signal component (SC) and lognormal distribution for NC as shown below:

$$
A(\Delta I)=\frac{A_{\mathrm{SC}}}{\sqrt{2 \pi} \sigma_{\mathrm{SC}}} e^{-\frac{\left(\Delta I+\mu_{\mathrm{SC}}\right)^{2}}{2 \sigma_{\mathrm{SC}}{ }^{2}}}+\frac{A_{\mathrm{SC}}}{\sqrt{2 \pi} \sigma_{\mathrm{SC}}} e^{-\frac{\left(\Delta I-\mu_{\mathrm{SC}}\right)^{2}}{2 \sigma_{\mathrm{SC}}}}+\frac{A_{\mathrm{NC}}}{\sqrt{2 \pi} \sigma_{\mathrm{NC}}|\Delta I|} e^{-\frac{\left(\mathrm{ln}|\Delta I|-\mu_{\mathrm{NC}}\right)^{2}}{2 \sigma_{\mathrm{NC}}{ }^{2}}}
$$


where $\Delta I$ is the relative difference intensity, $A(\Delta I)$ is the frequency for $\Delta I, \mu_{\mathrm{SC}}$ is the mean difference intensity of SC, $\sigma_{\mathrm{SC}}{ }^{2}$ is the variance of SC, $\mu_{\mathrm{NC}}$ is the logarithm of the median of the difference intensities of $\mathrm{NC}, \sigma_{\mathrm{NC}}{ }^{2}$ is the parameter giving the variance of $\mathrm{NC}$, and $A_{\mathrm{SC}}$ and $A_{\mathrm{NC}}$ are the amplitudes of the respective distributions of SC and NC. Assuming that NC was included regardless of the state of the sample, all the histograms in Figure 2 were globally fitted with Eq. S2, where the parameters for the NC ( $A_{\mathrm{NC}}, \mu_{\mathrm{NC}}$, and $\left.\sigma_{\mathrm{NC}}\right)$ were global. Because the fitting did not converge if $\mu_{\mathrm{SC}}$ and $\sigma_{\mathrm{SC}}$ were free, they were also set to be global parameter.

Kinetic Analysis. In the histograms of the probability distribution of duration times in $\mathrm{F}_{\text {high }}$ and $\mathrm{F}_{\text {low }}$ for photoactivated states and opsin states (Figures 3a-3d), significant amount of noise component (NC) overlapped signal component (SC) (Figure 2). To analyze the kinetics involving SC and NC, we generated the equilibrium model in which $\mathrm{F}_{\text {high }}$ and $\mathrm{F}_{\text {low }}$ are composed of two substates showing relatively high and low fluorescence intensity ( $\mathbf{H}$ and $\mathbf{H}^{\prime}$ for $\mathbf{F}_{\text {high, }}$, and $\mathbf{L}$ and $\mathbf{L}^{\prime}$ for $\mathrm{F}_{\text {low }}$, respectively) (Figure S3). In the boiled sample, fluorescence changes are derived only from NC between $\mathbf{D}$ and $\mathbf{D}^{\prime}$. In this scheme, the fluorescence conversions between $\mathbf{H}$ and $\mathbf{H}^{\prime}, \mathbf{L}$ and $\mathbf{L}^{\prime}$, and $\mathbf{D}$ and $\mathbf{D}^{\prime}$ are assumed to be derived from false detections. Therefore, $k_{\mathrm{s} 1}, k_{\mathrm{s} 2}, k_{\mathrm{s} 1}$, and $k_{\mathrm{s} 2}$ are the rate constants of fluorescence changes of SC, while $k_{\mathrm{N} 1}, k_{\mathrm{N} 2}, k_{\mathrm{N} 1}^{\prime}, k_{\mathrm{N} 2}^{\prime}, k_{\mathrm{N} 1}^{\prime}$, and $k_{\mathrm{N} 2}^{\prime \prime}$ are those of NC.

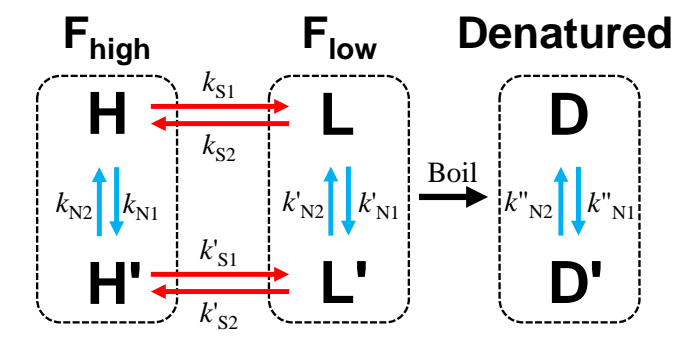

Figure S3. Equilibrium model used to analyze the duration time histogram.

We also assumed that $k_{\mathrm{N}}$ is stochastic and independent of the species $\left(k_{\mathrm{N} 1}=k_{\mathrm{N} 1}^{\prime}=k^{\prime \prime}{ }_{\mathrm{N} 1}\right.$ and $\left.k_{\mathrm{N} 2}=k_{\mathrm{N} 2}^{\prime}=k^{\prime \prime}{ }_{\mathrm{N} 2}\right)$. Because $\mathbf{H}$ and $\mathbf{H}^{\prime}$ (or $\mathbf{L}$ and $\mathbf{L}^{\prime}$ ) are seemingly different but essentially the same species, they are assumed to convert to $\mathbf{L}$ and $\mathbf{L}^{\prime}$ (or $\mathbf{H}$ and $\mathbf{H}^{\prime}$ ), respectively, with the same rate constant $k_{\mathrm{S} 1}=k_{\mathrm{S} 1}^{\prime}$ (or $k_{\mathrm{s} 2}=k_{\mathrm{s} 2}$ ). The photobleach of Alexa594 fluorophore, which possibly affects the apparent rate constants, was not taken into consideration for simplification, because the effect of bleach is relatively small. ${ }^{15}$ In this model, the fractions of $\mathbf{H}, \mathbf{H}$ ', $\mathbf{L}$, and $\mathbf{L}$ ' in the equilibrium mixture are expressed as follows: 


$$
\left\{\begin{array}{l}
{[\mathbf{H}]=\frac{k_{\mathrm{N} 2}}{k_{\mathrm{N} 1}+k_{\mathrm{N} 2}} \times \frac{k_{\mathrm{S} 2}}{k_{\mathrm{S} 1}+k_{\mathrm{S} 2}}} \\
{\left[\mathbf{H}^{\prime}\right]=\frac{k_{\mathrm{N} 1}}{k_{\mathrm{N} 1}+k_{\mathrm{N} 2}} \times \frac{k_{\mathrm{S} 2}}{k_{\mathrm{S} 1}+k_{\mathrm{S} 2}}} \\
{[\mathbf{L}]=\frac{k_{\mathrm{N} 2}}{k_{\mathrm{N} 1}+k_{\mathrm{N} 2}} \times \frac{k_{\mathrm{S} 1}}{k_{\mathrm{S} 1}+k_{\mathrm{S} 2}}} \\
{\left[\mathbf{L}^{\prime}\right]=\frac{k_{\mathrm{N} 1}}{k_{\mathrm{N} 1}+k_{\mathrm{N} 2}} \times \frac{k_{\mathrm{S} 1}}{k_{\mathrm{S} 1}+k_{\mathrm{S} 2}}}
\end{array}\right.
$$

Fluorescence decrease resulted from the conversions from $\mathbf{H}$ to $\mathbf{L}, \mathbf{H}$ to $\mathbf{H}^{\prime}, \mathbf{H}^{\prime}$ to $\mathbf{L}^{\prime}$, and $\mathbf{L}$ to $\mathbf{L}^{\prime}$. The frequency of fluorescence decrease due to conversion in the equilibrium mixture is expressed as follows:

$$
\left\{\begin{array}{l}
f_{\mathrm{H} \rightarrow \mathrm{L}}=k_{\mathrm{S} 1} \times[\mathbf{H}]=\frac{k_{\mathrm{S} 1} k_{\mathrm{S} 2} k_{\mathrm{N} 2}}{\left(k_{\mathrm{S} 1}+k_{\mathrm{S} 2}\right)\left(k_{\mathrm{N} 1}+k_{\mathrm{N} 2}\right)} \\
f_{\mathrm{H} \rightarrow \mathrm{H}^{\prime}}=k_{\mathrm{N} 1} \times[\mathbf{H}]=\frac{k_{\mathrm{S} 2} k_{\mathrm{N} 1} k_{\mathrm{N} 2}}{\left(k_{\mathrm{S} 1}+k_{\mathrm{S} 2}\right)\left(k_{\mathrm{N} 1}+k_{\mathrm{N} 2}\right)} \\
f_{\mathrm{H} \rightarrow \mathrm{L}^{\prime}}=k_{\mathrm{S} 1} \times\left[\mathbf{H}^{\prime}\right]=\frac{k_{\mathrm{S} 1} k_{\mathrm{S} 2} k_{\mathrm{N} 1}}{\left(k_{\mathrm{S} 1}+k_{\mathrm{S} 2}\right)\left(k_{\mathrm{N} 1}+k_{\mathrm{N} 2}\right)} \\
f_{\mathrm{L} \rightarrow \mathrm{L}^{\prime}}=k_{\mathrm{N} 1} \times[\mathbf{L}]=\frac{k_{\mathrm{S} 1} k_{\mathrm{N} 1} k_{\mathrm{N} 2}}{\left(k_{\mathrm{S} 1}+k_{\mathrm{S} 2}\right)\left(k_{\mathrm{N} 1}+k_{\mathrm{N} 2}\right)}
\end{array}\right.
$$

On the other hand, the velocities of the conversion of each state resulting in the fluorescence decrease are expressed as follows:

$$
\left\{\begin{array}{l}
\frac{d[\mathbf{H}]}{d t}=-\left(k_{\mathrm{S} 1}+k_{\mathrm{N} 1}\right)[\mathbf{H}] \\
\frac{d\left[\mathbf{H}^{\prime}\right]}{d t}=-k_{\mathrm{S} 1}\left[\mathbf{H}^{\prime}\right] \\
\frac{d[\mathbf{L}]}{d t}=-k_{\mathrm{N} 1}[\mathbf{L}]
\end{array}\right.
$$

Therefore, the probability distribution (duration time histogram) of fluorescence decrease $\left(f_{\text {high } \rightarrow \text { low }}(t)\right)$ is expressed as follows: 


$$
\begin{aligned}
f_{\text {high } \rightarrow \text { low }}(t) & =\left(k_{\mathrm{S} 1}+k_{\mathrm{N} 1}\right)\left(f_{\mathrm{H} \rightarrow \mathrm{L}}+f_{\mathrm{H} \rightarrow \mathrm{H}^{\prime}}\right) \exp \left\{-\left(k_{\mathrm{S} 1}+k_{\mathrm{N} 1}\right) t\right\}+k_{\mathrm{S} 1} f_{\mathrm{H}^{\prime} \rightarrow \mathrm{L}^{\prime}} \exp \left(-k_{\mathrm{S} 1} t\right)+k_{\mathrm{N} 1} f_{\mathrm{L} \rightarrow \mathrm{L}^{\prime}} \exp \left(-k_{\mathrm{N} 1} t\right) \\
& =\left(k_{\mathrm{S} 1}+k_{\mathrm{N} 1}\right) \frac{k_{\mathrm{S} 1} k_{\mathrm{S} 2} k_{\mathrm{N} 2}+k_{\mathrm{S} 2} k_{\mathrm{N} 1} k_{\mathrm{N} 2}}{\left(k_{\mathrm{S} 1}+k_{\mathrm{S} 2}\right)\left(k_{\mathrm{N} 1}+k_{\mathrm{N} 2}\right)} \exp \left\{-\left(k_{\mathrm{S} 1}+k_{\mathrm{N} 1}\right) t\right\}+k_{\mathrm{S} 1} \frac{k_{\mathrm{S} 1} k_{\mathrm{S} 2} k_{\mathrm{N} 1}}{\left(k_{\mathrm{S} 1}+k_{\mathrm{S} 2}\right)\left(k_{\mathrm{N} 1}+k_{\mathrm{N} 2}\right)} \exp \left(-k_{\mathrm{S} 1} t\right) \\
& +k_{\mathrm{N} 1} \frac{k_{\mathrm{S} 1} k_{\mathrm{N} 1} k_{\mathrm{N} 2}}{\left(k_{\mathrm{S} 1}+k_{\mathrm{S} 2}\right)\left(k_{\mathrm{N} 1}+k_{\mathrm{N} 2}\right)} \exp \left(-k_{\mathrm{N} 1} t\right)
\end{aligned}
$$

Similarly, the frequency of fluorescence increase ( $\mathbf{L}$ to $\mathbf{H}, \mathbf{H}^{\mathbf{\prime}}$ to $\mathbf{H}, \mathbf{L}^{\prime}$ to $\mathbf{H}^{\prime}$, and $\mathbf{L}^{\prime}$ to $\mathbf{L}$ ) in the equilibrium and the velocity of conversion resulting in the fluorescence increase are expressed as follows:

$$
\begin{aligned}
& \left\{\begin{array}{l}
f_{\mathrm{L} \rightarrow \mathrm{H}}=k_{\mathrm{S} 2} \times[\mathbf{L}]=\frac{k_{\mathrm{S} 1} k_{\mathrm{S} 2} k_{\mathrm{N} 2}}{\left(k_{\mathrm{S} 1}+k_{\mathrm{S} 2}\right)\left(k_{\mathrm{N} 1}+k_{\mathrm{N} 2}\right)} \\
f_{\mathrm{H} \rightarrow \mathrm{H}}=k_{\mathrm{N} 2} \times\left[\mathbf{H}^{\prime}\right]=\frac{k_{\mathrm{S} 2} k_{\mathrm{N} 1} k_{\mathrm{N} 2}}{\left(k_{\mathrm{S} 1}+k_{\mathrm{S} 2}\right)\left(k_{\mathrm{N} 1}+k_{\mathrm{N} 2}\right)} \\
f_{\mathrm{L}^{\prime} \rightarrow \mathrm{H}^{\prime}}=k_{\mathrm{S} 2} \times\left[\mathbf{L}^{\prime}\right]=\frac{k_{\mathrm{S} 1} k_{\mathrm{S} 2} k_{\mathrm{N} 1}}{\left(k_{\mathrm{S} 1}+k_{\mathrm{S} 2}\right)\left(k_{\mathrm{N} 1}+k_{\mathrm{N} 2}\right)} \\
f_{\mathrm{L}^{\prime} \rightarrow \mathrm{L}}=k_{\mathrm{N} 2} \times\left[\mathbf{L}^{\prime}\right]=\frac{k_{\mathrm{S} 1} k_{\mathrm{N} 1} k_{\mathrm{N} 2}}{\left(k_{\mathrm{S} 1}+k_{\mathrm{S} 2}\right)\left(k_{\mathrm{N} 1}+k_{\mathrm{N} 2}\right)}
\end{array}\right. \\
& \left\{\begin{array}{l}
\frac{d\left[\mathbf{L}^{\prime}\right]}{d t}=-\left(k_{\mathrm{S} 2}+k_{\mathrm{N} 2}\right)\left[\mathbf{L}^{\prime}\right] \\
\frac{d[\mathbf{L}]}{d t}=-k_{\mathrm{s} 2}[\mathbf{L}] \\
\frac{d\left[\mathbf{H}^{\prime}\right]}{d t}=-k_{\mathrm{N} 2}\left[\mathbf{H}^{\prime}\right]
\end{array}\right.
\end{aligned}
$$

Therefore, duration time histogram of fluorescence increase is expressed as follows:

$$
\begin{aligned}
f_{\text {low } \rightarrow \text { high }}(t) & =\left(k_{\mathrm{S} 2}+k_{\mathrm{N} 2}\right)\left(f_{\mathrm{L}^{\prime} \rightarrow \mathrm{H}^{\prime}}+f_{\mathrm{L}^{\prime} \rightarrow \mathrm{L}}\right) \exp \left\{-\left(k_{\mathrm{S} 2}+k_{\mathrm{N} 2}\right) t\right\}+k_{\mathrm{S} 2} f_{\mathrm{L} \rightarrow \mathrm{H}} \exp \left(-k_{\mathrm{S} 2} t\right)+k_{\mathrm{N} 2} f_{\mathrm{H}^{\prime} \rightarrow \mathrm{H}} \exp \left(-k_{\mathrm{N} 2} t\right) \\
& =\left(k_{\mathrm{S} 2}+k_{\mathrm{N} 2}\right) \frac{k_{\mathrm{S} 1} k_{\mathrm{S} 2} k_{\mathrm{N} 1}+k_{\mathrm{S} 1} k_{\mathrm{N} 1} k_{\mathrm{N} 2}}{\left(k_{\mathrm{S} 1}+k_{\mathrm{S} 2}\right)\left(k_{\mathrm{N} 1}+k_{\mathrm{N} 2}\right)} \exp \left\{-\left(k_{\mathrm{S} 2}+k_{\mathrm{N} 2}\right) t\right\}+k_{\mathrm{S} 2} \times \frac{k_{\mathrm{S} 1} k_{\mathrm{S} 2} k_{\mathrm{N} 2}}{\left(k_{\mathrm{S} 1}+k_{\mathrm{S} 2}\right)\left(k_{\mathrm{N} 1}+k_{\mathrm{N} 2}\right)} \exp \left(-k_{\mathrm{S} 2} t\right) \\
& +k_{\mathrm{N} 2} \times \frac{k_{\mathrm{S} 2} k_{\mathrm{N} 1} k_{\mathrm{N} 2}}{\left(k_{\mathrm{S} 1}+k_{\mathrm{S} 2}\right)\left(k_{\mathrm{N} 1}+k_{\mathrm{N} 2}\right)} \exp \left(-k_{\mathrm{N} 2} t\right) \quad(\mathrm{S} 22)
\end{aligned}
$$

In the boiled sample, the fluorescence change is derived only from the NC. In the equilibrium mixture,

$$
\begin{aligned}
& {[\mathbf{D}]=\frac{k_{\mathrm{N} 2}}{k_{\mathrm{N} 1}+k_{\mathrm{N} 2}}} \\
& {\left[\mathbf{D}^{\prime}\right]=\frac{k_{\mathrm{N} 1}}{k_{\mathrm{N} 1}+k_{\mathrm{N} 2}}}
\end{aligned}
$$


For the conversion of each substate,

$$
\left\{\begin{array}{l}
f_{\mathrm{D} \rightarrow \mathrm{D}^{\prime}}=f_{\mathrm{D}^{\prime} \rightarrow \mathrm{D}}=\frac{k_{\mathrm{N} 1} k_{\mathrm{N} 2}}{k_{\mathrm{N} 1}+k_{\mathrm{N} 2}} \\
\frac{d[\mathbf{D}]}{d t}=-k_{\mathrm{N} 1}[\mathbf{D}] \\
\frac{d\left[\mathbf{D}^{\prime}\right]}{d t}=-k_{\mathrm{N} 2}\left[\mathbf{D}^{\prime}\right]
\end{array}\right.
$$

Therefore,

$$
\left\{\begin{array}{l}
f_{\text {high } \rightarrow \text { low }}(t)=k_{\mathrm{N} 1} f_{\mathrm{D} \rightarrow \mathrm{D}^{\prime}} \exp \left(-k_{\mathrm{N} 1} t\right)=\frac{k_{\mathrm{N} 1}{ }^{2} k_{\mathrm{N} 2}}{k_{\mathrm{N} 1}+k_{\mathrm{N} 2}} \exp \left(-k_{\mathrm{N} 1} t\right) \\
f_{\text {low } \rightarrow \text { high }}(t)=k_{\mathrm{N} 2} f_{\mathrm{D}^{\prime} \rightarrow \mathrm{D}} \exp \left(-k_{\mathrm{N} 2} t\right)=\frac{k_{\mathrm{N} 1} k_{\mathrm{N} 2}^{2}}{k_{\mathrm{N} 1}+k_{\mathrm{N} 2}} \exp \left(-k_{\mathrm{N} 2} t\right)
\end{array}\right.
$$

The sets of duration time histograms of fluorescence decrease and increase of photoactivated state and opsin of $\mathrm{WT}^{\mathrm{C} 140 \mathrm{~S}}$ and M257Y $\mathrm{Y}^{\mathrm{C} 140 \mathrm{~S}}$ were fitted with the set of Eqs. S30 and S31, which are the products of amplification constant (A) and Eq. S14, and A and Eq. S22, respectively.

$$
\left\{\begin{array}{l}
f_{\text {high } \rightarrow \text { low }}(t)=A \frac{k_{\mathrm{S} 2} k_{\mathrm{N} 2}\left(k_{\mathrm{S} 1}+k_{\mathrm{N} 1}\right)^{2} \exp \left\{-\left(k_{\mathrm{S} 1}+k_{\mathrm{N} 1}\right) t\right\}+k_{\mathrm{S} 1}{ }^{2} k_{\mathrm{S} 2} k_{\mathrm{N} 1} \exp \left(-k_{\mathrm{S} 1} t\right)+k_{\mathrm{S} 1} k_{\mathrm{N} 1}{ }^{2} k_{\mathrm{N} 2} \exp \left(-k_{\mathrm{N} 1} t\right)}{\left(k_{\mathrm{S} 1}+k_{\mathrm{S} 2}\right)\left(k_{\mathrm{N} 1}+k_{\mathrm{N} 2}\right)} \\
f_{\text {low } \rightarrow \text { high }}(t)=A \frac{k_{\mathrm{S} 1} k_{\mathrm{N} 1}\left(k_{\mathrm{S} 2}+k_{\mathrm{N} 2}\right)^{2} \exp \left\{-\left(k_{\mathrm{S} 2}+k_{\mathrm{N} 2}\right) t\right\}+k_{\mathrm{S} 1} k_{\mathrm{S} 2}{ }^{2} k_{\mathrm{N} 2} \exp \left(-k_{\mathrm{S} 2} t\right)+k_{\mathrm{S} 2} k_{\mathrm{N} 1} k_{\mathrm{N} 2}{ }^{2} \exp \left(-k_{\mathrm{N} 2} t\right)}{\left(k_{\mathrm{S} 1}+k_{\mathrm{S} 2}\right)\left(k_{\mathrm{N} 1}+k_{\mathrm{N} 2}\right)}
\end{array}\right.
$$

On the other hand, set of duration time histograms of fluorescence decrease and increase of boiled sample was fitted with the set of Eqs. 32 and 33, the products of $A$ and Eq. S28, and $A$ and Eq. S29, respectively.

$$
\left\{\begin{array}{l}
f_{\text {high } \rightarrow \text { low }}(t)=A \frac{k_{\mathrm{N} 1}^{2} k_{\mathrm{N} 2}}{k_{\mathrm{N} 1}+k_{\mathrm{N} 2}} \exp \left(-k_{\mathrm{N} 1} t\right) \\
f_{\text {low } \rightarrow \text { high }}(t)=A \frac{k_{\mathrm{N} 1} k_{\mathrm{N} 2}^{2}}{k_{\mathrm{N} 1}+k_{\mathrm{N} 2}} \exp \left(-k_{\mathrm{N} 2} t\right)
\end{array}\right.
$$

In these fittings, $k_{\mathrm{S} 1}$ and $k_{\mathrm{s} 2}$ were common in each sample, while $k_{\mathrm{N} 1}, k_{\mathrm{N} 2}$ and $A$ were global among all samples. The results of fitting are summarized in Table S1. 
Table S1. Kinetic Parameters of the Conformational Changes.

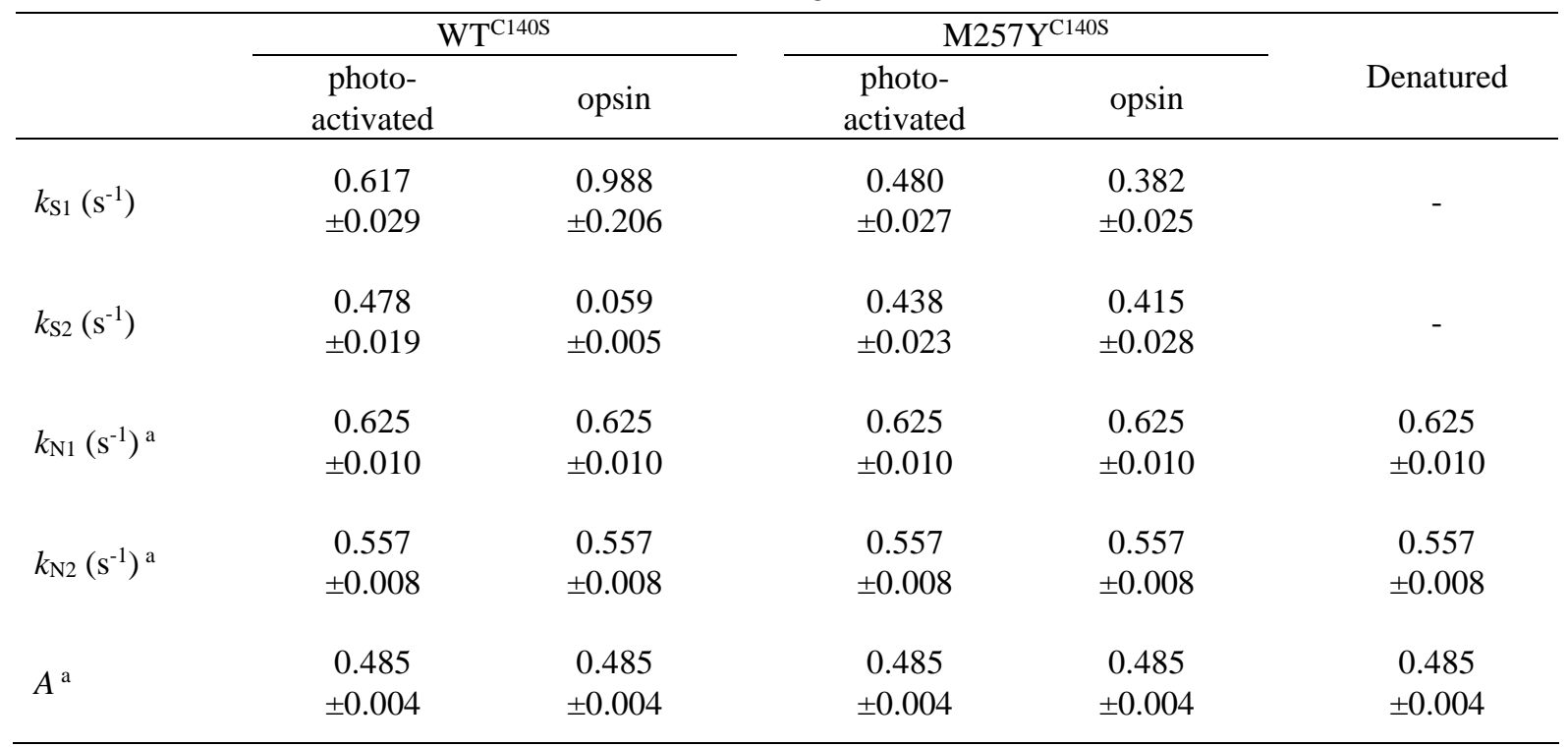

${ }^{a}$ Global variables.

Validation of the Kinetic Analysis. This kinetic analysis was intended to separate SC from NC to estimate the rate constants of conformational change. To validate this analysis, the ratio of occurrence of fluorescence changes derived from SC and NC in each sample was calculated in two different ways. Using $k_{\mathrm{s} 1}$, $k_{\mathrm{S} 2}, k_{\mathrm{N} 1}$, and $k_{\mathrm{N} 2}$ obtained from the global fitting analysis, the ratio of the occurrence of SC and NC $\left(\frac{f_{\text {Signal }}}{f_{\text {Noise }}}\right)$ was calculated as follows:

$\frac{f_{\text {Signal }}}{f_{\text {Noise }}}=\frac{f_{\mathrm{H} \rightarrow \mathrm{L}}+f_{\mathrm{H}^{\prime} \rightarrow \mathrm{L}^{\prime}}}{f_{\mathrm{H} \rightarrow \mathrm{H}^{\prime}}+f_{\mathrm{L} \rightarrow \mathrm{L}^{\prime}}}=\frac{f_{\mathrm{L} \rightarrow \mathrm{H}}+f_{\mathrm{L}^{\prime} \rightarrow \mathrm{H}^{\prime}}}{f_{\mathrm{H}^{\prime} \rightarrow \mathrm{H}}+f_{\mathrm{L}^{\prime} \rightarrow \mathrm{L}}}=\frac{k_{\mathrm{S} 1} k_{\mathrm{S} 2}\left(k_{\mathrm{N} 1}+k_{\mathrm{N} 2}\right)}{k_{\mathrm{N} 1} k_{\mathrm{N} 2}\left(k_{\mathrm{S} 1}+k_{\mathrm{S} 2}\right)}$

On the other hand, the ratio of the occurrence of SC and NC is also calculated using the areas of SC (Figures 2a and 2b, green) and NC (Figures 2a and 2b, blue) in the difference intensity histograms ( $\left.\frac{A_{\text {Signal }}}{A_{\text {Noise }}}\right)$. The results are summarized in Table S2 and Figure S4. $\frac{f_{\text {Signal }}}{f_{\text {Noise }}}$ and $\frac{A_{\text {signal }}}{A_{\text {Noise }}}$ are in good agreement with each other, showing the validity of our kinetic analysis. 


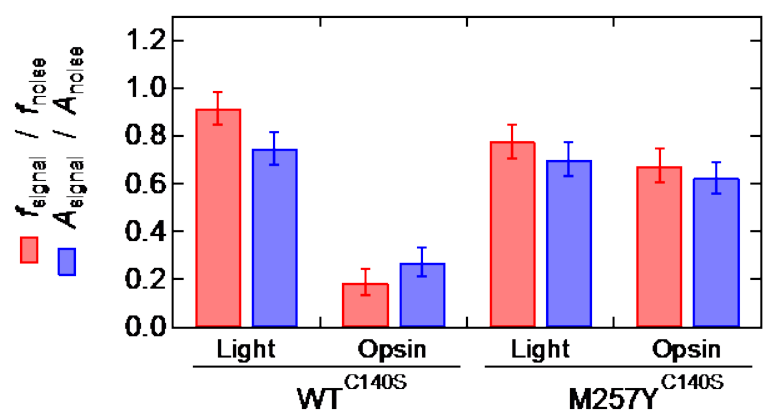

Figure S4. The ratio of the occurrence of fluorescence changes derived from SC and NC. It was calculated using $k_{\mathrm{S} 1}, k_{\mathrm{S} 2}, k_{\mathrm{N} 1}$, and $k_{\mathrm{N} 2}$ obtained by the global fitting analysis (red) or areas of SC and NC (Eq. S2) in the different intensity histograms (blue).

Table S2. Ratio of the Occurrence of Fluorescence Changes Derived from Signal and Noise Components.

\begin{tabular}{cccccc}
\hline & \multicolumn{2}{c}{$\mathrm{WT}^{\mathrm{C} 140 \mathrm{~S}}$} & & \multicolumn{2}{c}{$\mathrm{M} 257 \mathrm{Y}^{\mathrm{C} 140 \mathrm{~S}}$} \\
\cline { 2 - 3 } $\begin{array}{c}\text { photo- } \\
\text { activated }\end{array}$ & opsin & & $\begin{array}{c}\text { photo- } \\
\text { activated }\end{array}$ & opsin \\
\hline$\frac{f_{\text {Signal }}}{f_{\text {Noise }}}$ & 0.914 & 0.190 & & 0.777 & 0.676 \\
& \pm 0.067 & \pm 0.056 & & \pm 0.070 & \pm 0.073 \\
$\frac{A_{\text {Signal }}}{A_{\text {Noise }}}$ & 0.748 & 0.273 & & 0.703 & \\
\hline
\end{tabular}

